experience (which has been of sporadic cases in fairly acute stages) the fluid is clear. Under the microscope the cellular elements are seen to be increased, lymphocytes being characteristic of tuberculous and polymorphonuclear leucocytes of meningococcic meningitis. Tubercle bacilli are hard to find without repeated and careful examination, but meningococci may be readily seen.

In conclusion, I may say that I have not attempted to deal with all the obscure causes of fever in childhoodthey are far too numerous for that; but I have chosen conditions which in my experience are of great difficulty and importance. I may not have said much that is new, I have made no serious attempt to do that, having in mind rather t?:e promotion of discussion and the gain to our knowledge thereby.

\section{A STUDY OF AN EPIDEMIC OF MEASLES.}

ART'HCR EDWIN TAIT, M.B., Сh.B.EDIN.,

RESIDENT MEDICAL OFFICER, DRANCH DISPENSARY, CHELTENHAM GENERAL HOSPITAI.

Having had the opportunity of dealing with a severe epidemic of measles, I make no apology for publishing my experiences over well-trodden ground. The total number of cases observed was 437.

In the table and chart I have grouped togcther as pulmonary complications, bronchitis, pneumonia, and broncho-

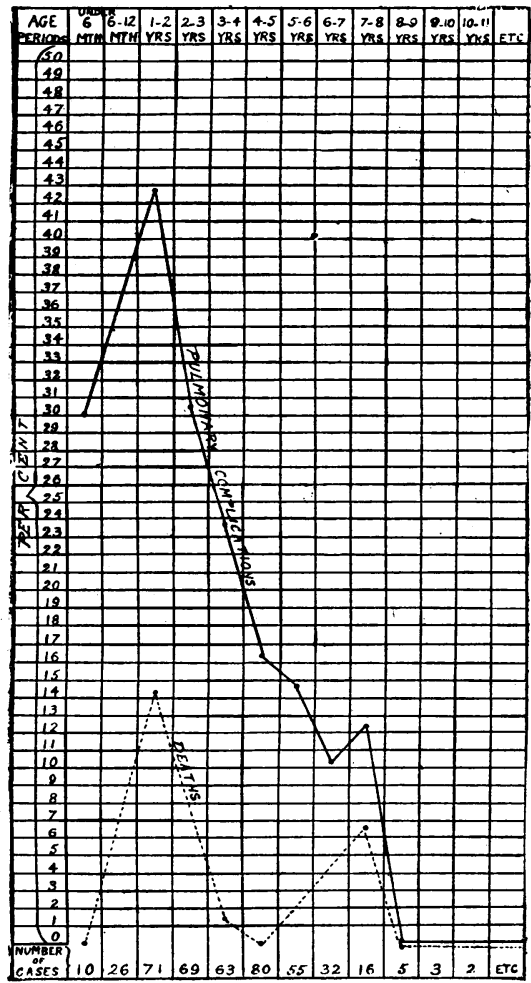
pneumonia, excluding croup, laryngitis, aud catarils; the former proving the death producers. In the accompanying percentage chart it is clearly shown that death depends on these pulmonary complications. In the first fire years of life the fact is remarkable that the curres of pulmonary complications and death percent. a ge s a ro parallel, so exact is the relation between them. The maximum in the second year of life is very striking. The cases under the age of 6 months -2.29 per cent. of all casesoccurred as young as 2 wonths. Some attacks were severe. One commenced with a profuse rash with epistaxis and laryngeal catarrh, diarrhoea and bronchopneumonia followed. Recovery took place. I attribute the apparent immunity of babies under 6 months to the comparative isolation of cradle life.

Cases werc most numerous in the fourth year of life, with 16 per cent. pulmonary complications, and no deaths. 'The total death-rate of the cpidemic was 5.03 per cent., and all the deaths cxcept two occurred before the end of June. The death-rate before the end of June was 5.31 per cent. and afterwards 327 per cent. The two deaths after June 30 th were in the second year of life. The death-rate in the second year of life was 14.08 per cent., and was 12.5 in the early months, with 42.1 per cent. pulmonary complications. 'The high death-rate in the second year is not sur- prising, therefore. And this is probably the solution to the controversy as to the abnornally high mortality from measles-namely, 15.4 per cent.-of those treated in the Metropolitan Asylums Board fever hospitals in the early months of 1911. These are the severe cases for which the poorer classes would be only too glad to avail themselves of hospital treatment. There were hundreds of mild cases in this district this year untreated, An analysis of ages, condition on admission, and mortality of the Metropolitan Asylums Board hospital cases would be instructive.

Apart from catarrh and laryngitis, severe pulmonary complications supervened in 23.57 per cent. of all cases; 25.5 pcr cent. in the early months. Pneumococcal infection is the cause of measles mortality. After Jume 30th a considerable fall in pneumosoccal infections and their severity brought down the deatli-rate, although there were as many smart attacks of measles per se.

Ten cases of pnenmococcal infection ran to a crisis with recovely out of the total of 104 cases. The remainde varied in type, depending on the virulence of infection, resistancc of patickt, and presence or absence of diarrhoea Some caseis occurred a few hour's after the appearance of the rash, producing a temperature of $102^{\circ}, 103^{\circ}$, or $104^{\circ}$, with acute dyspnoea and death within three or four days. A large number hung on for wecks and months with unresolved bronchopneumonia, which had come on a fer days to a week from the commencement of the rash, the temperature gradually over a week rising to $102^{\circ}$, swinging about this for two or three weelse, and gradually falling to normal. The pulse and respirations remainer frequent for some time after the temperature had fallen to normal. These protracted cases, especially when carcful nursing was available, nearly all recovered; sorry wrecks doubtless, but they pulled up wonderfully if treated for some time afterwards. Even children orie suspected were tubcrculous recovered. I always gave an optimistic prognosis in protracted cases; and when they appeared in a dying condition, emaciated, frequent varying pulse, swinging temperature, laboured respirations, râles in the lungs, and often refusing food, and apparently hopeless, I never lost hope. They nearly all recovered eventually. One of these, after two montlis' illness, succumbed to an operation in the neck for suppurating glands. In these protracted cases a diligent search for tubercle bacilli was made, but never once discovered - a point of some interest in the light of recent controversy as to the presence of active tuberculosis in the lungs of children. Fraenkel's pneumococcus was always present in abundance.

Empyema was conspicuous by its absence. Middleear disease was common, but was amenable to fomentations, mild lotions, and hexamethylenetetramine internally. Diarrhoea occurred in 10 per cont. of cases during invasion, with the rash, or afterwards, and sometimes during incubation. Alarming croupy symptoms with the rash sometimes occurred, but quickly subsided. Most dangerous were those cases which with mild coryzal symptoms and rash, apparently a mild attack, when on the sccond or third day of rash acute dys'moea suddenly appeared, a rise in temperature, uncountable pulse, and great restlessness, often ending in death in twenty-four to forty-eight hour's. They are now, I believe, assigned to collapse of lung.

One of these cases examined post mortem showed no collapse of lung to the naked eye. This child simulated laryngeal obstruction so completely that I watched it all one night through, and had everything in readiness for tracheotomy, which was not required. Five and a half days fiom onset of rash the child died, passing into unconsciousness the last day. The larynx and trachea were quite frec. The lungs were studled with yellowish-grer specks under the pleura, the size of an ordinary pin's head. Little fluid in pleural sacs, and some sticky exudate stretching across the cavity like cobwebs. The lungs were pale. Frothy blood could be squeezell out, and mucopurvent plugs from bronchioles. Bronchial glands slightly enlarged. Pericardium externally markedly injecter. Sac smooth, and full of albuminous yellow fluid. 'The stomach showed slight catarrh, also the intestines in places. Blood clark and fluid. Heart muscle pale. Thrombus extending from auricles to ventricles. Brain showed venous congestion, and some sticky exudate. The hemispheres and lobes were cemented together. The blood post mortem showed numerous pneumoccci. A smear from the laryngeal wall showed plentiful Micrococcus telrageus and pneumococci; also lous chains of bacilli as long as the chains of the pnoumo long chains of bacilli as long as the chains of the pneumococci themselves. These long bacilli showed beaded structure and Gram-stained. 
If cases of this type hung on for any length of time they recovered. One boy, aged 3, with dyspnoea, swollen fauces, and rise of temperature, struggled for breath two weeks. There may have been some bronchopneumonia present not apparent to percussion and auscultation. It was two months before he was out of danger, but he completely recovered. It was the quickly acting, virulent, pneumococcal infection that killed perhaps mostly in weakly children. Death, if it happened, occurred three to ten days after the rash appeared.

One boy, aged 7 , had a mild attack. On the third day he was almost felled like an ox with sickness and semiconsciousness, which next day passed into complete unconsciousness, rapid noisy breathing, and passing of faeces and urine in the bed. He never regained consciousness, and died two day's later. I diagnosed pneumccoccal meningitis.

His sister suffered from measles also, and three days after her brother's death became suddenly ill with severe bronchopneumonia and laryngeal symptoms. She recovered tardily without tracheotomy after life had been despaired of.

In this epidemic epistaxis occurred in 10 per cent. of cases-in the mildest as well as serere cases. It had nothing to do with the haemorrhagic form of measles. I s.w no other form of haemorrhage. I soon learnt to use it as a distinct sign of measles, and of use to differentiate a case from rötheln or scarlet fever. It came on just before the rash was visible, or within twelve hours of its appearance; rarely as late as twenty-four hours. Sometimes, but not often, it was severe. Une case bled rather copiously at intervals from 10 p.m. till 6 a.m. Koplik's spots were no use to me. Irregular, opaque, pinkish spots on the mucous membrane of the mouth were common on the second and third days.
Three cases developed a swollen condition of lips and cheek, such as one has seen go on to cancrum oris. They recovered without sloughing.

One child contracted measles while convalescent in fever hospital from diphtheria, and had a very mild attack. One boy, 18 months, had a mixed rash of measles and scarlet fever, septic throat, enlarged glands in the neck, and severe bronchopneumonia ; he desquamated all over thinly, and subsequently suffered from discharging ears. After two months' severe illness he made a complete recovery. Three cases lost the use of their legs in late convalescence, with reflexes abolished, flaccidity of limbs, and pain on handling limbs. One in both legs; two in one leg (poliomyelitis).

A naevus-coloured rash, usually confluent, was common, making a "blue child." It occurred in every kind of case. I never saw a case of measles without cough more or less distressing. Small abscesses in the eyelids, arising in connexion with $\epsilon$ yelashes, occurred in a dozen cases.

One case went on to red, puffy swelling of both evelids, with purulent discharge.

Another had badly swollen eyelid, with red inflammatory involvement of nose and nasal duct.

Enlarged glands in the neck were not troublesome. All cases tabulated had a definite history of three or four di ys' previous illness before the rash appeared, coryzal signs and symptoms, cough and characteristic rash. Rash vas delayed a day or two in one case, agcd 13 months, which proved fatal in seven days from its appearance-from bronchopneumonia.

One case of interest, not in this epidemic, was that of a girl, aged 11 , who had a mixed rash of measles and scarlet fever, little temperature, no sore throat, and not a characteristic scariet fever tongue. On the fourth day acute articular rheumatism occurred. The swollen knees and wrists were not very painful. In three more days a profuse crop of chicken-pox appeared.

Cases Occurring February 13th to June 30th, 1911.

\begin{tabular}{|c|c|c|c|c|c|c|c|c|c|c|c|c|c|c|c|}
\hline \multirow{2}{*}{\multicolumn{2}{|c|}{$\cdots \quad-$}} & & \multicolumn{4}{|c|}{ Males. } & \multicolumn{4}{|c|}{ Eemales. } & \multicolumn{4}{|c|}{ Males and Females. } \\
\hline & & & & $\begin{array}{c}\text { No. } \\
\text { of } \\
\text { Cases. }\end{array}$ & 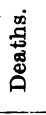 & $\begin{array}{c}\text { Mortality } \\
\text { per } \\
\text { Cent. }\end{array}$ & $\begin{array}{c}\text { Pulmonary } \\
\text { Com- } \\
\text { plications. }\end{array}$ & $\begin{array}{c}\text { No. } \\
\text { of } \\
\text { Cases. }\end{array}$ & 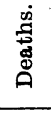 & $\begin{array}{c}\text { Mcrtality } \\
\text { per } \\
\text { Cent. }\end{array}$ & $\begin{array}{c}\begin{array}{c}\text { Pulmonary } \\
\text { Com- } \\
\text { plications. }\end{array} \\
- \\
\end{array}$ & $\begin{array}{c}\text { No. } \\
\text { of } \\
\text { Cases. }\end{array}$ & 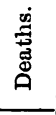 & $\begin{array}{c}\text { Mortality } \\
\text { per } \\
\text { Cent. }\end{array}$ & $\begin{array}{l}\text { Pulmonary } \\
\text { Com. } \\
\text { plications.* }\end{array}$ \\
\hline \multirow{2}{*}{$\begin{array}{l}\text { Under } 6 \text { months } \\
6 \text { to } 12 \text { months }\end{array}$} & $\therefore$ & $\ldots$ & $\ldots$ & 5 & - & - & 3 & 3 & - & - & - & 8 & - & - & 3 \\
\hline & $\ldots$ & $\ldots$ & $\ldots$ & 9 & 2 & 22.0 & 5 & 14 & - & - & 3 & 23 & 2 & 8.6 & 8 \\
\hline 1 to 2 years... & $\cdots$ & $\cdots$ & $\ldots$ & 39 & 5 & 12.8 & 18 & 25 & 3 & 12.0 & 9 & 64 & 8 & 12.5 & $27(42.1 \%)$ \\
\hline 2 to 3 years ... & $\cdots$ & $\cdots$ & $\ldots$ & 27 & 2 & 7.4 & 7 & 30 & 4 & 13.3 & 11 & 57 & 6 & 10.52 & 18 \\
\hline \multirow{2}{*}{$\begin{array}{l}3 \text { to } 4 \text { years ... } \\
4 \text { to } 5 \text { years ... }\end{array}$} & $\cdots$ & $\cdots$ & $\ldots$ & 28 & - & - & 6 & 27 & 1 & 3.7 & 9 & 55 & 1. & 1.81 & 15 \\
\hline & $\cdots$ & $\cdots$ & $\cdots$ & 39 & - & 一 & 6 & 32 & - & - & 7 & 71 & - & - & 13. \\
\hline \multicolumn{4}{|c|}{ Totals under 5 years... } & 147 & 9 & 6.12 & 45 & $131^{\circ}$ & 8 & 6.10 & 39 & 278 & 17 & 6.11 & $84(30.2 \%)$ \\
\hline \multirow{2}{*}{$\begin{array}{l}5 \text { to } 10 \text { years } \\
10 \text { to } 15 \text { years }\end{array}$} & $\cdots$ & $\ldots$ & $\ldots$ & 41 & 1 & 2.43 & 6 & 52 & 2 & 3.84 & 6 & 93 & 3 & 3.22 & 12 \\
\hline & $\ldots$ & $\ldots$ & $\cdots$ & 1 & - & - & - & 3 & - & - & - & 4 & - & - & - \\
\hline Over 15 years & $\ldots$ & $\ldots$ & $\ldots$ & - & - & - & - & 1 & - & - & - & 1 & - & 二. & 二 \\
\hline \multirow{2}{*}{ Total ov } & er 5 & ears & $\ldots$ & 42 & 1 & 2.38 & 6 & 56 & 2 & 3.57 & 6 & 98 & 3 & 3.06 & 12 \\
\hline & $1 \mathrm{ag}$ & & $\cdots$ & 189 & 10 & 5.29 & 51 & 187 & 10 & 5.34 & 45 & 376 & 20 & 5.31 & $96(25.53 \%)$ \\
\hline
\end{tabular}

Cases Occurring July 1st to August 20th.

\begin{tabular}{|c|c|c|c|c|c|c|c|c|c|c|c|c|c|c|c|}
\hline Under 6 months . & $\cdots$ & $\cdots$ & $\cdots$ & - & - & - & - & 2 & - & - & - & 2 & - & - & - \\
\hline 6 to 12 months. & $\ldots$ & ... & $\because$ & 2 & - & -- & 1 & 1 & - & - & - & 3 & - & - & 1 \\
\hline 1 to 2 years ... & $\cdots$ & $\cdots$ & $\ldots$ & 3 & - & - & 1 & 4 & 2 & 50.0 & 2 & 7 & 2 & 28.57 & 3 \\
\hline 2 to 3 years ... & $\ldots$ & $\ldots$ & $\ldots$ & 6 & - & - & 1 & 6 & - & - & 2 & 12 & - & - & 3 \\
\hline 3 to 4 years ... & $\cdots$ & $\ldots$ & $\ldots$ & 3 & - & - & - & 5 & - & - & - & 8 & - & - & - \\
\hline 4 to 5 years ... & $\ldots$ & $\ldots$ & $\ldots$ & 3 & - & - & $\therefore$ & 6 & - & - & - & 9 & - & - & - \\
\hline \multicolumn{4}{|c|}{ Totals under 5 years ... } & 17 & - & - & 3 & 24 & 2 & 8.33 & 4 & 41 & 2 & 4.87 & 7 \\
\hline 5 to 10 years & $\cdots$ & $\cdots$ & $\cdots$ & 9 & - & - & - & 8 & - & - & - & 17 & - & - & - \\
\hline 10 to 15 years & $\cdots$ & $\cdots$ & $\cdots$ & - & - & - & - & 3 & - & - & 1 & 3 & - & - & 1 \\
\hline Over 15 years & $\cdots$ & $\cdots$ & $\ldots$ & - & - & - & - & 一 & - & - & - & - & - & - & - \\
\hline \multirow{2}{*}{\multicolumn{4}{|c|}{$\begin{array}{l}\text { Totals over } 5 \text { years } \\
\text { Totals all ages ... }\end{array}$}} & 9 & - & - & - & 11 & - & - & 1 & 20 & - & - & 1 \\
\hline & & & & 26 & - & - & 3 & 35 & 2 & 5.7 & 5 & 61 & 2 & 3.27 & $8(13.1 \%)$ \\
\hline \multicolumn{3}{|c|}{ Total of epidemic } & $\cdots$ & 215 & 10 & 4.65 & 54 & 222 & 12 & 5.40 & 50 & 437 & 22. & 5.03 & $104(23.79 \%)$ \\
\hline
\end{tabular}

* Pulmonary complications includes definite bronchitis, pneumonia, and bronchopneumonia only. 
She desquamated profusely, and made an easy and complete recovery.

About 15 per cent. of cases were stated to have had measles before. Erythema nodosum on the front of the tibia occurred in numerous cases after measles in children of rheumatic tendency.

\section{Treatment.}

Copious and frequent application of nearly saturated borax solution to mouth, eyes, and nose. Rest in bed ten days after appearance of l'ash and confined to house for two weeks unless complications ensued. Jacket linseed poultices I found of great value in the pulmonary complications, followed by a Gamgee jacket in protracted cases. Brandy, in failing pulse and emaciated cases, and often when no other food could be taken, was of the utmost value. Cough mixtures were given as a routine practice containing squills, ipecacuanha, belladonna, potassium and ammonium carbonate, and liquorice. Tinct. nucis vomicae was added when necessary. I give full notes of the following case, as one of great interest, showing the ten days' struggle from the onset of the rash of a healthy child:

Girl, aged 18 months. Called to her on June 24th. She had the usual history and had had slight diarrhoea for two days. The rash was well out when I saw her. On June $28 \mathrm{th}$, fifth day of rash, the temperature was $101^{\circ} \mathrm{F}$., respirations 30 , and snuffling in type; pulse 130 . Diarrhoea continued in spite of breathing got worse and she began to be restless. The chest sounds were loud and harsh on inspiration with bronchitic rhonchi. No dullness. On July 2nd a few streaks of blood appeared in motions, and although diarrhoea was much improved the child became semicomatose with great restlessness. Cough was not very severe. Temperature never high, $101^{\circ}$ to $102^{\circ} \mathrm{F}$. On July 3rd diarrhoea was under control, but in the evening, while at stool, on giving a cough, the mother noticed, a swelling in the face and sought me late at noticed a swelling in the face and sought me late at
night. I found the child collapsed, dusky, and breathing disnight. I found the child collapsed, dusky, and breathing distressfully. The left cheek appeared swollen like a large gumboil. The right cheek was slightly puffy. A further examination revealed a goitrous-like neck, which extended round to the back on both sides and tapered off to the spines of the scapulae.
On feeling these swellings their true nature was at once apparent by the crackling feel under the fingers-surgical emphy. sema. Chest back and front were hyper-resonant. I did not think the child would survive the night. Next day the emphysema had blown out both cheeks to the zygoma and tapered off quickly into the scalp: It passed round to the inion and back of neck. The child died July 3 rd at 11.30 a.m

Necropsy, July 4th, 1911.-Well nourished body; rigidity passed off; buttocks irritated by discharges; surgical emphysema, the knife passing through subcutaneous tissues with crackling sound, like cutting raw blown veal. Some air had penetrated beneath the pectoral muscles. On removing the sternum the external surface of the pericardium was seen to be studded with air vesicles, like bunches of very seen to be studded with air vesicles, like bunches of very small grapes. The lungs also, but more discrete. In the No fluid in pleural sacs. In one place the lung tissue for ao thuid in pleural sacs. In one place the lung tissue for about in. was as if cut in two and connected by two thin transparent membranes. The anterior aspect of the upper the lung surface-was most affected, and the lower pole. The apices and posterior border were little affected. The " dog's tongue "was blown out into a bladder. The middle lobe of right lung was similarly affected to the upper lobes. The lower lobes of both lungs contained scarcely any blebs, and presented a nearly normal appearance, except for a bleb or two. (The air pressure, therefore, was least in apices, posterior border, and lower lobe.) The roots of the lungs were a mass of blebs. root-bleb in the left chest had burst. (Pneumothorax was not diagnosed during life; both lungs were equally hyper-resonant. From the roots of the lungs the blebs were continuously presen in all directions, passing upwards into neck and face, and down in all directions, passing upwards into neck and face, and down along the aorta through diaphragm, getting more scarce, but a few blebs reached around the kidneys, and even behind the rectum. The pericardial sac contained 3iv of yellowish albuminous fluid. The interior of sac and healt surface presented a biled patches on valve; free border thickened and red, with smooth lentil-sized nodules (2)-swelling, not deposit. Aortic valve normal. Tricuspid and pulmonary valves similar to mitral, but no nodules. A firm white clot adherent to the auricular appendix passed into and filled the left ventricle, adhering to the papillae, and passing $1 \frac{1}{2}$ in. into the aorta. Right heart same condition, reaching from auricle to beyond the bifurcation of the pulmonary artery. Section of lung showed no solid raised patches, large or small. Plugs of muco-purulent matter could be expressed from the bronchioles. The lungs were spongy, and frothy bloody fluid exuded. Trachea contained a moderate layer of reddish muco-purulent matter. Larynx similar, with some caked on drab coloured parts. Epiglottis swollen, and also vocal mechanism (vocal cords unrecognizable). Spleen
dark and firm. Liver, boiled appearance. Kidneys also, and dark and firm. Liver, boiled appearance. Kidneys also, and showed hyperaemic patches of mucosa at entrance and exit, and contained yellowish fluid. A foot along the jejunum a small patch of hyperaemia, and occasionally a patch, until one
reached the last 4 in. of the ileum, where there was marked hyperaemia and a little ecchymosis. The caecum and hyperaemia and a little ecchymosis. The caecum and ascending colon were similarly severely involved. Patches of
the same nature, but slighter, occurred in the rest of the the same nature, but slighter, occurred in the rest of the
intestine. No peritonitis, no fluid in abdomen. No enlarged intestine. No peritonitis, no fluid in abdomen. No enlarged
glands. Appendix normal. Very little air had penetrated glands. Appendix normal. Very little air had penetrated venous congestion only. The blood taken post mortem showed an intense leucocytosis, mainly polymorphs; numerous pneumococci were free in the blood and in the leucocytes. A smear from the laryngeal wall showed plentiful supply of Nicrococci tetrageni and pneumococci. Also long streptothrix chains (unbranched), eight to ten times as long as the pneumococci chains; each member of the chain a bacillus with beaded appearance, and as long as six pneumococci, and Gram-staining. Tracheal smear showed the same fauna. The smear from the exudate from the bronchiole showed pneumococci only, as also exudate from the bronch
did the pericardial fluid.

\section{ANEURYSM OF THE SUPERIOR MESENTERIC ARTERY, WITH RUPTURE.}

\section{By ALEX. H. GIFFORD, Mi.R.C.S.ENG., L.R.C.P.LoND.}

SENIOR MEDICAL OFFICER, ADDINGTON HOSPITAL, DURBAN.

ANEurysus of the abdominal aorta, near the coeliac axis, are described as occurring in nearly equal proportions communicating with the anterior and posterior parts of the aorta, but I can find no description of an aneurysm of the superior mesenteric artery. The following is a case of aneurysm of the superior mesenteric artery associated with an aortic aneurysm, with rupture into the lesser sac of the peritoneum.

\section{History.}

A Kaffir woman, aged about 33 years, came into hospital com plaining of pain and throbbing in the epigastric region, where she had "noticed" a lump for a week. 'The pain in the abdomen had been felt for three months; it had no relation to the taking of food, but her appetite had been very bad; the bowels had been this region, and no history of syphilis.

\section{Physical Signs and Symptoms.}

A tumour the size of an orange was seen and felt in the ep gastric region, slightly to the left of the middle line; it was firm, and incompressible on moderate pressure, with a somewhat irregular conformation; there was a strong expansile mpulse synchronous with the heart's beats. The tumour wa immovable, both from above downwards and laterally. On light percussion there was no resonance. The

rmly pushed against the anterior abdominal wall. " " but tho days later there was a return of this symptom, with constant severe pain, which was referred to the spine in the lumbar region, and to the sides of the abdomen about the same level. The patient died eight clays after admission.

\section{Necrops?}

At the post-mortem examination a fusiform aneurysm of the abdominal aorta was found at and around the origin of the coeliac axis and superior mesenteric arteries.

The opening of the coeliac axis artery lay in the right side of the aortic aneurysmal sac, and was normal in size and shape ; artery was a large orifice, 2 in. in length and $1 \frac{1}{2}$ in. in width, opening into a larger, irregular, oblong-shaped aneurysmal cavity, the measurements of which were $4 \mathrm{in}$. from right to left, 3 in. from above downwards, with a depth of $2 \mathrm{in}$. from before backwards. In addition there was a conical prolongation downwards and to the right, : which was continuous with the anteroduodenal portion of the suljerior mesenteric artery. Another prolongation of the cavity extended upwards below, then to the prolongation of the cavity extended upwards below, then to the right of and finally above the coeliac axis artery and its
branches. This prolongation extended up as far as the inferior branches. This prolongation extended up as far as the inferior
surface of the liver, and it was at its upper part that the rupture surface of the liver, and it was at its upper part

This large aneurysmal cavity was bounded anteriorly by the head, neck, and body of the pancreas, and by the posterior layer of the lesser sac of the peritoneum; posteriorly the cavity was formed by muscles and various tissues matted together, superiorly the liver, and inferiorly the transverse part of the duodenum and the mesentery bounded the cavity, whilst the right side was

The rupture took place into the lesser sac by a transverse opening $\frac{1}{2}$ in: in length at the upper part of the cavity, just under the liver, the edges being much thickened and somewhat valvular.

The blood, after rupturing into the lesser sac of the peritoneum, had found its way through the foramen of Winslow into the peritoneal cavity, where about two handfuls of clot and a pint of serum were found at the post-mortem examination. 